\title{
The role of surfactants in the formulation of
} \section{elastic liposomal gels containing a synthetic opioid analgesic}

This article was published in the following Dove Press journal:

International Journal of Nanomedicine

8 April 2016

Number of times this article has been viewed

\author{
Sima Singh ${ }^{1, *}$ \\ Harsh Vardhan ${ }^{1, *}$ \\ Niranjan G Kotla ${ }^{2}$ \\ Balaji Maddiboyina ${ }^{3}$ \\ Dinesh Sharma ${ }^{4}$ \\ Thomas J Webster ${ }^{5,6}$ \\ 'School of Pharmaceutical Sciences, \\ Lovely Professional University, \\ Phagwara, India; ${ }^{2}$ Center for \\ Research in Medical Devices, \\ National University of Ireland, \\ Galway, Ireland; ${ }^{3}$ Department of \\ Pharmaceutics, Vishwabharathi \\ College of Pharmaceutical Sciences, \\ Guntur, India; ${ }^{4}$ Ranbaxy Laboratory \\ Ltd, Gurgaon, India; ${ }^{5}$ Department of \\ Chemical Engineering, Northeastern \\ University, Boston, MA, USA; ${ }^{6}$ Center \\ of Excellence for Advanced Materials \\ Research, King Abdulaziz University, \\ Jeddah, Saudi Arabia \\ *These authors contributed equally \\ to this work
}

\begin{abstract}
Transdermal drug delivery systems have made significant contributions to the medical community, but have yet to completely substitute oral or parenteral delivery. Recently, various strategies have been used to augment the transdermal delivery of therapeutics. Primarily, they include iontophoresis, electrophoresis, sonophoresis, chemical permeation enhancers, microneedles, and vesicular systems. Among these strategies, elastic liposomes appear promising. Elastic vesicle scaffolds have been developed and evaluated as novel topical and transdermal delivery systems, with an infrastructure consisting of hydrophobic and hydrophilic moieties together, and as a result, such scaffolds can accommodate drug molecules with a wide range of solubility. High deformability of these vesicles provides for better penetration of intact vesicles. This system is much more efficient at delivering low- and high-molecular-weight drugs to the skin in terms of quantity and depth. In this work, elastic liposomes of Tramadol $\mathrm{HCl}$ were prepared using a solvent evaporation method with different surfactants and were characterized using microscopy, and particle size, shape, drug content, ex vivo release, and zeta potential were also calculated. The prepared elastic liposomes were found to be in the range of $152.4 \mathrm{~nm}$ with a zeta potential of $-22.4 \mathrm{mV}$; the entrapment efficiencies of the selected formulation was found to be $79.71 \% \pm 0.27 \%$. All formulations in the form of a gel were evaluated for physicochemical properties and were found to be homogeneous with no grittiness, and the $\mathrm{pH}$ of all formulations was found to be neutral. The optimized selected elastic liposomal formulation followed the Higuchi equation and Fickian diffusion and released the drug for a period of 24 hours. The overall results provide much promise for the continued investigation of deformable vesicles as transdermal drug carriers.
\end{abstract}

Keywords: elastic liposome, skin delivery, occlusion, hydration-gradient, hydrogel

\section{Introduction}

Adverse side effects, poor drug metabolism, poor patient compliance, or rejection of invasive medication often hamper the success and efficacy of therapeutic treatments. To overcome the aforementioned problems, many drug carriers have been developed, but some carriers such as liposomes, niosomes, or microemulsions remain mostly confined to the skin surface and therefore do not transport drugs efficiently through the skin. ${ }^{1}$ To overcome this problem resulting from the stratum corneum barrier, various approaches have been adopted. These include augmentation of skin permeability using penetration enhancers, use of forces which are not dependent on concentration gradients (iontophoresis, electroporation, phonophoresis, microneedles, jet injectors, etc) and, more recently, changes in the drug carrier itself (such as using vesicles). ${ }^{2}$

Drug delivery systems using vesicular carriers have soft, flexible, self-regulating, and self-optimizing vesicular characteristics. Greater flexibility of elastic liposomal
Correspondence: Thomas J Webster Department of Chemical Engineering, Northeastern University, 360 Huntington Avenue, 021 15-2989, Boston, MA, USA Tel +l 6173736585

Email th.webster@neu.edu
International Journal of Nanomedicine 2016: | | |475-|482 Dovepress http://dx.doi.org/| 0.2147/IJN.SI 00253 (c) (1) (5) 2016 Singh et al. This work is published and licensed by Dove Medical Press limited. The full terms of this license are available at https://www.dovepress.com/terms.php cc) ${ }_{\mathrm{BY}} \mathrm{NC}$ and incorporate the Creative Commons Attribution - Non Commercial (unported, v3.0) License (http://creativecommons.org/licenses/by-nc/3.0/). By accessing the work you hereby accept the Terms. Non-commercial uses of the work are permitted without any further permission from Dove Medical Press Limited, provided the work is properly attributed. For permission for commercial use of this work, please see paragraphs 4.2 and 5 of our Terms (https://www.dovepress.com/terms.php). 
membranes is achieved by mixing suitable surface-active components in the proper ratios. ${ }^{3}$ These properties allow them to penetrate more easily into deeper layers of the skin and circulation.

An elastic liposome carrier is described as a lipid droplet of such deformability that it permits easy penetration through pores much smaller than the droplet size and also it is a highly adaptable and stress-responsive, complex aggregate. They are elastic, very deformable vesicles which consist of soya phosphatidylcholine (SPC) in combination with an edge-active surfactant like sodium cholate and span 80 . An edge activator is usually a single chain surfactant that causes the destabilization of the lipid bilayer of the vesicle and increases the vesicle-elasticity or fluidity by lowering its interfacial tension. ${ }^{4}$

Flexibility of an elastic liposome membrane is achieved by mixing suitable surface-active agents in the proper ratios. These are modified forms of the liposome which consist of both hydrophilic and hydrophobic properties, greater deformability than the standard liposomes and are well suited for skin permeation. These self-optimized aggregates with ultraflexible membranes are able to deliver the drug reproducibly with high efficiency either into or through the skin depending on the choice of administration or application. ${ }^{5}$

Tramadol is a synthetic opioid analgesic proposed for moderate-to-severe pain. Recent data demonstrated that its opioid activity is the overriding contributor to its pharmacological activity. As a consequence, numerous reports of abuse and dependence have been received. ${ }^{6}$ Topical dosage forms are desirable for the chronic use of this drug, especially in the case of rheumatic symptoms. ${ }^{7}$ Moreover, the biological activity of the drug was maintained at a dose of at least one order of magnitude lower than that commonly used in commercial topical lotions or creams. As a result, it may be anticipated that any systemic side effects would be greatly reduced. The elastic liposome is a good alternative for the combined oral and topical administration of the drug for rheumatoid diseases. It has been shown that delivery from elastic liposomes caused a sustained prolonged therapeutic effect resulting in a higher drug concentration in the skin than that from commercial gels and ointments. ${ }^{8}$ Because of the abovementioned reasons, the objective of this study was to prepare an elastic liposomal gel containing tramadol $\mathrm{HCl}$ (a synthetic opioid analgesic) and carry out physical evaluation as well as ex vivo drug release, including stability studies of the prepared formulations. Here, SPC span 80, Tween 80 , and sodium deoxycholate (SDC) were selected as components of the elastic liposome, and tramadol $\mathrm{HCl}$ was selected as model drug for the elastic liposome formulation. An ex vivo permeation and stability study were also performed.

\section{Materials and methods Materials}

Tramadol HCl was obtained from Jackson Pharm. Pvt. Ltd, Amritsar. SPC was a kind gift from Lipoid, GmBH, Ludwigshafen. Span 80, sodium deoxycholate, Tween 80, Carbopol 934, Triton-X 100, triethanolamine, chloroform, and methanol were all purchased from Loba Chemie (P) Ltd, Mumbai, India.

\section{Preparation of elastic liposomes}

The molar ratios of SPC or soya lecithin and surfactants were accurately weighed as summarized in Table 1 and were dissolved at the minimum quantity (about $10-30 \mathrm{~mL}$ )

Table I Ratio of different variables in the formulation and optimization of drug-loaded elastic liposomes

\begin{tabular}{|c|c|c|c|c|c|c|c|}
\hline \multirow[t]{2}{*}{ Formulation } & \multicolumn{7}{|l|}{ Variables } \\
\hline & Drug (mg) & $\begin{array}{l}\text { SPC } \\
(\% \mathrm{w} / \mathrm{w})\end{array}$ & $\begin{array}{l}\text { Hydration } \\
(15 \mathrm{~mL})\end{array}$ & $\begin{array}{l}\text { Span } 80 \\
(\% \text { w/w) }\end{array}$ & $\begin{array}{l}\text { SDC } \\
(\% \mathrm{w} / w)\end{array}$ & $\begin{array}{l}\text { Tween } 80 \\
(\% \text { w/w) }\end{array}$ & $\begin{array}{l}C: M \\
(2: I) m L\end{array}$ \\
\hline $\mathrm{FI}$ & 100 & 85 & $7 \%$ ethanol & 15 & - & - & $20: 10$ \\
\hline F2 & 100 & 95 & $7 \%$ ethanol & 5 & - & - & $20: 10$ \\
\hline F3 & 100 & 85 & $7 \%$ ethanol & - & 15 & - & $20: 10$ \\
\hline $\mathrm{F} 4$ & 100 & 95 & $7 \%$ ethanol & - & 5 & - & $20: 10$ \\
\hline F5 & 100 & 85 & $7 \%$ ethanol & - & - & 15 & $20: 10$ \\
\hline F6 & 100 & 95 & $7 \%$ ethanol & - & - & 5 & $20: 10$ \\
\hline F7 & 100 & 85 & PBS pH 6.4 & 15 & - & - & $20: 10$ \\
\hline F8 & 100 & 95 & PBS pH 6.4 & 5 & - & - & $20: 10$ \\
\hline F9 & 100 & 85 & PBS pH 6.4 & - & 15 & - & $20: 10$ \\
\hline FIO & 100 & 95 & PBS pH 6.4 & - & 5 & - & $20: 10$ \\
\hline FII & 100 & 85 & PBS pH 6.4 & - & - & 15 & $20: 10$ \\
\hline $\mathrm{FI} 2$ & 100 & 95 & PBS pH 6.4 & - & - & 5 & $20: 10$ \\
\hline
\end{tabular}

Abbreviations: SPC, soya phosphatidylcholine; SDC, sodium deoxycholate; C:M, chloroform:methanol; PBS, phosphate buffered saline. 
of a mixture of chloroform:methanol (2:1), along with the required dose of tramadol $\mathrm{HCl}$ in a $250 \mathrm{~mL}$ round bottom flask to obtain a clear solution. The round bottom flask was then attached to a rotary evaporator by means of an elastic plastic band. The rotary evaporator was evacuated with a vacuum for a few hours through a vacuum pump and was rotated at $100 \mathrm{rpm}$ with the round bottom flask immersed in a water bath. A thermostat was set at $60^{\circ} \mathrm{C}$, ie, above the phase transition temperature $\left(T_{\mathrm{m}}\right)$ of the phospholipids $\left(52^{\circ} \mathrm{C}\right)$ to obtain a thin dry lipid film. After complete evaporation of the solvent, the flask was kept under vacuum overnight to remove the residual solvent. Hydration of the dry lipid film was accomplished by adding phosphate-buffered saline (PBS) buffer at a $\mathrm{pH}$ of 6.4 or $7 \%$ ethanol and placing the flask on a rotary evaporation system for a period of 1 hour (hydration time) without vacuum, at a temperature $\left(60^{\circ} \mathrm{C}\right)$ higher than the $T_{\mathrm{m}}$ of the phospholipid. The resulting vesicles were swollen for 2 hours at room temperature and this produced a homogeneous milky yellowish/white suspension of multilamellar liposomes (MLVs) free of visible particles.

The hydration time was optimized such that there was enough swelling of the lipid film in order to obtain MLVs with more interlamellar distance. Once a stable MLV suspension was produced, it was subjected to ultrasonication by transferring the colloidal suspension onto a beaker. All molar ratios were optimized to obtain the best entrapment efficiency (EE). ${ }^{9-13}$

\section{Entrapment efficiency}

EE was determined by first separation of the unentrapped drug using centrifugation. After centrifugation, the vesicles were disrupted using Triton X-100 or 50\% n-propanol. The $\mathrm{EE}$ is expressed as:

$$
\% \mathrm{EE}=\frac{\text { Entrapped drug }}{\text { Total drug }} \times 100
$$

After sonication, the elastic liposomal suspension (SUVs) was collected in a centrifuge tube, and was centrifuged at $40,000 \mathrm{rpm}(1,370,088 \mathrm{G})$ for 30 minutes at $4{ }^{\circ} \mathrm{C}$ in an ultracold centrifuge (Optima LE-80K, Beckman Coulter Inc., Brea, CA, USA) at NIPER to obtain a white pellet of SUVs which settled at the bottom of the centrifuge tube. The supernatant was separated using a micropipette as it contained unentrapped drugs highly soluble in PBS at a $\mathrm{pH}$ of 6.4. To the remaining pellet in the centrifuge tube, PBS at a $\mathrm{pH}$ of 6.4 was added and then vortexed thoroughly for 3 minutes. After vortexing, a white suspension was obtained, and $1 \mathrm{~mL}$ of this suspension was taken in a micropipette and transferred to a test tube. To this, an appropriate amount of PBS at a pH of 6.4 and $1 \mathrm{~mL}$ of Triton-X-100 (1\% v/v) were added to ensure that the elastic liposomes were lysed completely to release the drug. This solution $(1 \mathrm{~mL})$ was further diluted with $\mathrm{PBS}$ at a $\mathrm{pH}$ of 6.4 , and finally the absorbance was determined using a UV spectrophotometer (Shimadzu 1800, Shimadzu Corporation, Kyoto, Japan). The EE was expressed as the percentage entrapment of the drug added.

$\mathrm{RCF} / \mathrm{g}$ : It is the force acting on the samples during centrifugation. It is expressed as multiples of the earth's gravitational field $(g)$ :

$$
\mathrm{RCF}=1.12 \times r(\mathrm{RPM} / 1,000)^{2}
$$

where $r$ is radius in millimeters $(76.5 \mathrm{~mm}$ for optima LE- $80 \mathrm{~K})$, RCF is relative centrifugal force, and $g$ is gravitation field.

\section{Vesicle size analysis}

Average particle size, size distribution, and zeta potential of the elastic liposomal suspension (SUVs) were measured using a Malvern Nano Zetasizer instrument (DTS Ver. 5.10, Malvern Instruments, Malvern, UK). Zeta potential was analyzed in order to study colloidal properties and stability of the vesicles. ${ }^{14,15}$

\section{Physical stability studies}

A stability study was carried out for the sonicated elastic liposomal suspension of SUVs at two different temperatures, ie, a refrigeration temperature $\left(5^{\circ} \mathrm{C} \pm 3^{\circ} \mathrm{C}\right)$ and a room temperature $\left(25^{\circ} \mathrm{C} \pm 2^{\circ} \mathrm{C}\right)$, for 8 weeks. Sampling was completed and suitable dilutions were made with $\mathrm{PBS}$ at a $\mathrm{pH}$ of 6.4, and UV absorbance was determined. The EE was calculated from the regression equation $Y=0.007 x$ obtained from the standard plot of tramadol $\mathrm{HCl}$ in $\mathrm{PBS}$ at a $\mathrm{pH}$ of 6.4 at $271 \mathrm{~nm}$.

\section{Microscopic analysis and transmission electron microscopy}

Elastic liposomes can be visualized by an optical light microscope (Kyowa [GETNER]). A drop of the prepared sample of the elastic liposomes was placed on a glass slide and carefully covered with a cover slip. The excess solution was drained off by using filter paper and was then observed by optical light microscopy. ${ }^{16}$

Transmission electron microscopy (TEM) studies were performed to establish a direct comparison of individual particle sizes of unsonicated and sonicated elastic liposomes. 
A drop of a sample was placed onto a carbon-coated copper grid along with a drop of $2 \%$ phosphotungstic acid to leave a thin film and the excess solution was then drained off using filter paper. The grid was allowed to air dry thoroughly, and the samples were then viewed using a Hitachi transmission electron microscope. TEM images and electron diffraction patterns were visualized and collected by soft imaging software. ${ }^{17}$

\section{Preparation of topical hydrogel}

An appropriate quantity of carbopol $934(0.25 \%, 0.50 \%$, $0.75 \%, 1 \%$, and $1.25 \%$ ) was added to $100 \mathrm{~mL}$ of distilled water. It was then left to swell and hydrate at room temperature for 2 hours to obtain a homogeneous mixture. Then, it was stirred for 60 minutes at $800 \mathrm{rpm}$, followed by the drop wise addition of a few $\mathrm{mL}$ of triethanolamine to neutralize the formulation. Mixing was continued until a transparent gel appeared. ${ }^{18,19}$

\section{Ex vivo and skin permeation studies}

An ex vivo study has been carried out to simulate the in vivo permeation conditions. Abdominal skin was obtained via abdominal incision from euthanised rats collected from an approved laboratory off site. The skin was immediately placed into ice-cold, bubbled (carbogen, 95:5 $\mathrm{O}_{2} / \mathrm{CO}_{2}$ ) cold saline. The elastic liposomal gel equivalent to $1 \mathrm{~mL}$ of optimized SUVs was applied to the epidermal surface of an albino rat abdominal skin in a vertical Franz diffusion cell. The other side of the abdominal skin was in contact with the dissolution medium. The entire dissolution assembly was placed on a magnetic stirrer at $37^{\circ} \mathrm{C} \pm 0.5^{\circ} \mathrm{C}$ and was agitated at $100 \mathrm{rpm}$. The effective permeation area of the donor cell exposed to the receptor cell was $3.14 \mathrm{~cm}^{2}$, and the dissolution medium was $100 \mathrm{~mL}$ of PBS at a $\mathrm{pH}$ of 6.4 . Aliquots $(5 \mathrm{~mL})$ of the dissolution medium were withdrawn from the sampling port at different time intervals $(5,10,15,30,45,60,120,240$, 480,720 , and 1,440 minutes). Whenever the sample was withdrawn, equal volumes of fresh dissolution medium was added to the beaker to maintain a constant volume. Drug concentrations in the dissolution medium were determined by a UV spectrophotometer at $271 \mathrm{~nm}$. All the experiments were carried out in triplicate and the results were expressed as the mean \pm standard deviation..$^{20-27}$

\section{Results and discussion Optimization of elastic liposomal preparation}

A total 12 batches of elastic liposomes were prepared by varying the 5 independent variables, ie, concentration of
SPC, SDC, Tween 80, Span 80, and hydration solvent for all possible combinations (Table 1) in order to evaluate their influence on dependent variables such as particle size, EE, and zeta potential. The concentrations of independent variables were based on the results obtained from preliminary literature studies.

\section{Particle size and zeta potential analysis}

Particle size analysis, polydispersity index, and zeta potential of the sonicated elastic liposomes were measured by dynamic light scattering using a Malvern Zetasizer instrument. Elastic liposomes were diluted with buffer before measurements. All measurements were taken at $165^{\circ}$ light scattering and at $25^{\circ} \mathrm{C}$. The average particle sizes, polydispersity index, and zeta potential of the sonicated elastic liposomes are listed in Table 2. The concentration of SPC seems to be one of the most dominant parameters influencing the particle size. Surfactant concentration holds an inverse relationship with particle size. Higher surfactant concentration also imparts stability against aggregation by rapidly covering the surface of newly generated elastic liposomes, thus protecting the liposomes from growing into larger ones. The reduction in polydispersity was noticed, and this might be attributed to the reduction of interfacial tension, ensuring a good emulsification process.

The zeta potential study depicts good stability of the vesicular formulations which lies within the desired millivolts range, as high surface charge prevents aggregation of the particles. ${ }^{28}$ The higher charge on the surface of the vesicles produced a repulsive force between the vesicles which made them stable and devoid of agglomeration.

Table 2 Particle size distribution and zeta potential analyzed using the Malvern instrument

\begin{tabular}{|c|c|c|c|c|}
\hline Formulation & $\begin{array}{l}\text { Size } \\
\text { distribution } \\
(\mathrm{nm})\end{array}$ & $\begin{array}{l}\text { Mean } \\
\text { intensity (\%) }\end{array}$ & PDI & $\begin{array}{l}\text { Zeta } \\
\text { potential } \\
(\mathrm{mV})\end{array}$ \\
\hline $\mathrm{FI}$ & $122.6 \pm 5.6$ & 67.3 & 0.18 & $-40.3 \pm 2.3$ \\
\hline F2 & $139.2 \pm 4.1$ & 56.7 & 0.16 & $-29.4 \pm 2.5$ \\
\hline F3 & $167.3 \pm 4.8$ & 100 & 0.23 & $-38.1 \pm 3.1$ \\
\hline $\mathrm{F} 4$ & $198.4 \pm 5.2$ & 89.2 & 0.20 & $-26.4 \pm 1.8$ \\
\hline F5 & $219.7 \pm 7.4$ & 78.4 & 0.24 & $-31.8 \pm 1.3$ \\
\hline F6 & $179.3 \pm 3.1$ & 92.8 & 0.18 & $-21.2 \pm 2.1$ \\
\hline F7 & $152.4 \pm 3.6$ & 100 & 0.25 & $-35.3 \pm 1.6$ \\
\hline F8 & $374.9 \pm 8.2$ & 71.3 & 0.28 & $-30.3 \pm 2.9$ \\
\hline F9 & $\mathrm{I}, 084 \pm 20.5$ & 100 & 0.19 & $-28.1 \pm 3.1$ \\
\hline FIO & $|0,695.2| \pm 32.5$ & 0.0 & 0.29 & $-25.2 \pm 2.6$ \\
\hline FII & $311.7 \pm 4.6$ & 71.9 & 0.19 & $-32.3 \pm 2.3$ \\
\hline $\mathrm{F} 12$ & $455.1 \pm 6.4$ & 82.3 & 0.21 & $-28.7 \pm 2.5$ \\
\hline
\end{tabular}

Note: Average of three determinations $\pm S D$.

Abbreviations: PDI, polydispersity index; SD, standard deviation. 


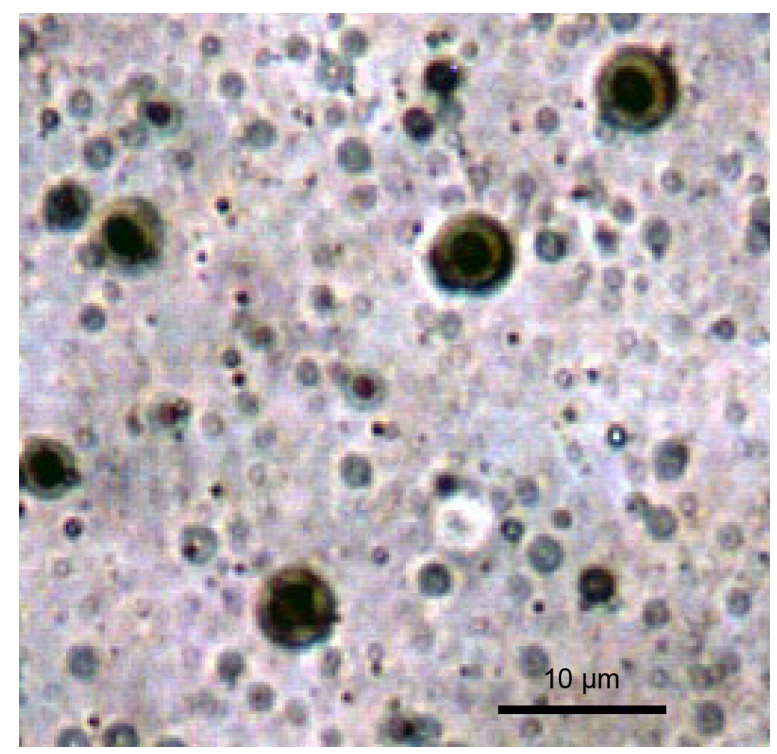

Figure I Optical microscopy of elastic liposomes (F7) at a I,000× magnification.

\section{Microscopic analysis}

The photographs of elastic liposomes were taken using an optical light microscope at 1,000× magnification (Figure 1), thus confirming the spherical uniformity of elastic liposome vesicles.

TEM images of the drug-loaded optimized elastic liposomal formulation (F7) shows the size and morphology of the vesicles, ie, all the vesicles were discrete, spherical in shape having uniform size, and exhibited a smooth surface without any rough pores (Figure 2).

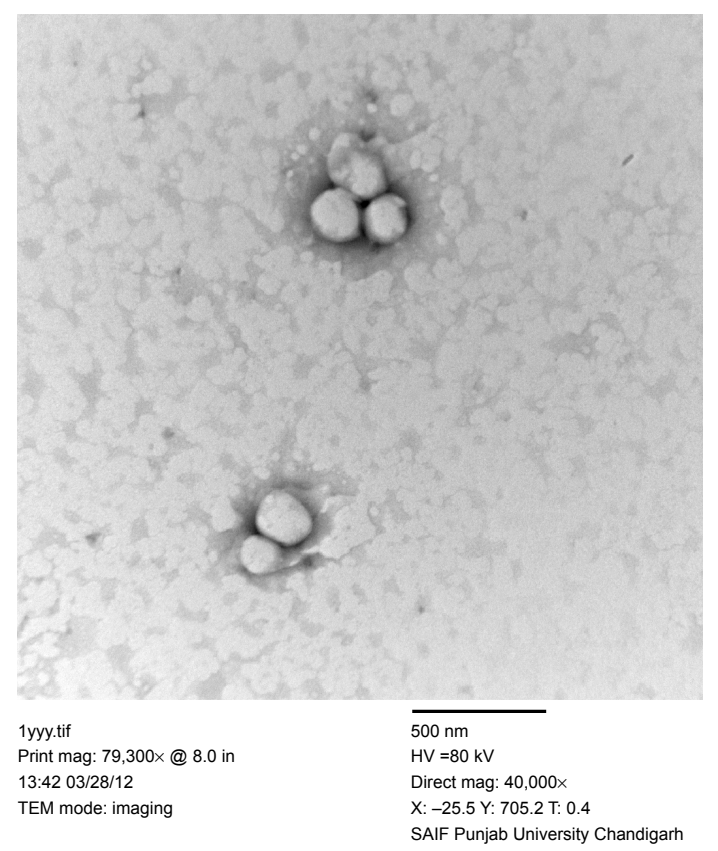

Figure 2 TEM micrographs of elastic liposomes (F7).

Abbreviation: TEM, transmission electron microscopy.
Table 3 Calculation for \% EE of Tramadol $\mathrm{HCl}$ in different formulations

\begin{tabular}{lll}
\hline Formulation & $\begin{array}{l}\text { Concentration } \\
(\mu \mathrm{g} / \mathrm{mL})\end{array}$ & \% EE $^{\mathrm{a}}$ \\
\hline FI & 50.428 & $75.64 \pm 0.85$ \\
F2 & 42.142 & $63.21 \pm 0.78$ \\
F3 & 37.285 & $55.92 \pm 0.09$ \\
F4 & 31.714 & $47.57 \pm 0.70$ \\
F5 & 26.857 & $40.28 \pm 0.56$ \\
F6 & 18.142 & $27.21 \pm 0.32$ \\
F7 & 53.142 & $79.71 \pm 0.27$ \\
F8 & 46.857 & $70.28 \pm 0.42$ \\
F9 & 40.142 & $60.21 \pm 0.34$ \\
FIO & 35.142 & $52.71 \pm 0.19$ \\
FII & 19.857 & $29.78 \pm 0.12$ \\
FI2 & 16.714 & $25.07 \pm 0.21$ \\
\hline
\end{tabular}

Note: ${ }^{a}$ Average of three determinations \pm SD.

Abbreviations: $E E$, entrapment efficiency; SD, standard deviation.

\section{Entrapment efficiency}

EE of the SUVs was determined by lysing the SUVs in PBS at a $\mathrm{pH}$ of 6.4 followed by further treatment with Triton-X100 (Table 3 and Figure 3). The drug content in the aqueous phase was measured by UV-Visible spectroscopy at $271 \mathrm{~nm}$. The enhanced EE with a relative increase in SPC concentration was observed on account of more availability of SPC for encapsulating the elastic liposomes. Conversely, the increase in surfactant concentration would have caused the EE to decrease.

Formulations $\mathrm{F} 1$ and $\mathrm{F} 7$ showed good $\mathrm{EE}$ as compared to the others (Figure 3). The maximum EE of the elastic liposomal formulation was found to be $79.71 \%$ for the F7 formulation. The composition and physicochemical properties of the topical hydrogels are listed in Tables 4 and 5, respectively.

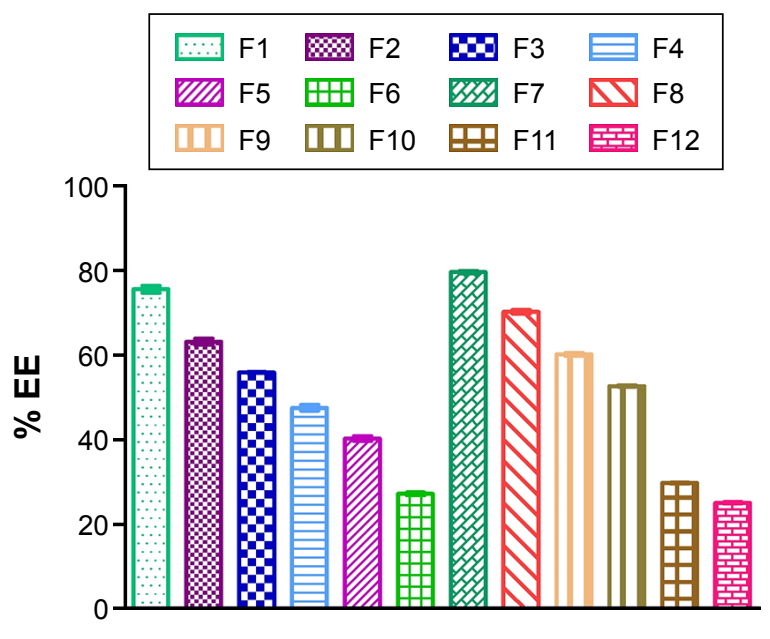

Formulations

Figure 3 Comparison of EE of various formulations.

Abbreviation: EE, entrapment efficiency. 
Table 4 Composition of topical hydrogel formulations

\begin{tabular}{lll}
\hline Components & \multicolumn{2}{l}{ Topical hydrogel formulations } \\
\cline { 2 - 3 } & FI & F7 \\
\hline Elastic liposome & $\mathrm{I} \mathrm{mL}$ SUVs & $\mathrm{I} \mathrm{mL}$ SUVs \\
Carbopol 934 $(\%)$ & 0.75 & 0.75 \\
Diethyl amine $(\mathrm{mg})$ & 0.5 & 0.5 \\
Distilled water $(\mathrm{mL})$ & 4 & 4 \\
\hline
\end{tabular}

Abbreviation: SUVs, small unilamellar vesicles.

\section{Stability studies}

The stability of the elastic liposomes is a major consideration in all steps of production and administration, from processing steps to storage to delivery. A stable dosage form maintains its physical integrity and does not adversely influence the chemical integrity of the active ingredient during its life on the shelf. As the elastic liposomes are thermodynamically unstable systems, they tend to fuse and grow into bigger vesicles resulting in breakage during storage, which clearly poses a problem of drug leakage from the vesicles.

Vesicle stability is a major determinant for the stability of the formulations; hence, this study was carried out to evaluate drug entrapment at room temperature $\left(25^{\circ} \mathrm{C} \pm 2^{\circ} \mathrm{C}\right)$ and refrigeration temperature $\left(5^{\circ} \mathrm{C} \pm 3^{\circ} \mathrm{C}\right)$. Stability could not be maintained at higher temperatures ( $>$ room temperature) because the phospholipid was used as the component for liposomes and deteriorated at higher temperatures.

The stability data of elastic liposomes at $5^{\circ} \mathrm{C} \pm 3^{\circ} \mathrm{C}$ and $25^{\circ} \mathrm{C} \pm 2^{\circ} \mathrm{C}$ are given in Table 6 . According to the data, formulations stored at refrigeration temperatures showed higher drug content when compared to the formulations stored at room temperature, after a period of 8 weeks.

\section{Ex vivo drug release studies}

Ex vivo drug release studies were carried out using a Franz diffusion cell in $100 \mathrm{ml}$ of $\mathrm{PBS}(\mathrm{pH} 6.4)$ at $37^{\circ} \mathrm{C} \pm 0.5^{\circ} \mathrm{C}$ (Table 7 and Figure 4). The surface-adsorbed drug showed

Table 5 Physicochemical characteristics of topical hydrogel formulations

\begin{tabular}{llll}
\hline Characteristics & $\begin{array}{l}\text { Evaluation } \\
\text { method }\end{array}$ & \multicolumn{2}{l}{$\begin{array}{l}\text { Topical hydrogel } \\
\text { formulations }\end{array}$} \\
\cline { 2 - 4 } & FI & F7 \\
\hline Homogenecity & Visual inspection & Good & Good \\
Grittiness & Optical microscopy & No & No \\
Clarity & Visual inspection & Clear & Clear \\
pH & Electric pH meter & $7.24 \pm 0.32$ & $7.72 \pm 0.50$ \\
Viscosity & Brookfield & $7,823.21$ cps & $8,231.23$ cps \\
& viscometer & & \\
Drug content (\%) & Flask shake method & $97.23 \pm 0.61$ & $96.18 \pm 0.29$ \\
\hline
\end{tabular}

Table 6 Stability data of elastic liposomal formulation F7

\begin{tabular}{lll}
\hline Entrapment study (\%) & & \\
\hline Days & $\mathbf{5}^{\circ} \mathbf{C} \pm \mathbf{3}^{\circ} \mathbf{C}$ & $\mathbf{2 5}^{\circ} \mathbf{C} \pm \mathbf{2}^{\circ} \mathbf{C}$ \\
\hline 0 & $79.71 \pm 0.27$ & $79.71 \pm 0.27$ \\
7 & $79.45 \pm 0.08$ & $78.21 \pm 1.91$ \\
15 & $79.02 \pm 0.22$ & $77.08 \pm 3.35$ \\
30 & $78.67 \pm 0.06$ & $76.42 \pm 1.71$ \\
45 & $78.04 \pm 0.17$ & $74.91 \pm 0.53$ \\
60 & $77.12 \pm 0.62$ & $71.32 \pm 1.74$ \\
\hline
\end{tabular}

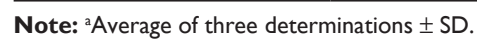

Abbreviation: SD, standard deviation.

an initial burst release with nearly $25 \%$ release within 1 hour due to faster diffusion followed by extended release over 24 hours.

Formulation F1 released $71.08 \%$ of the drug after 24 hours, whereas formulation F7 released $58.82 \%$ of the drug after 24 hours. Although the release profiles for both formulations did not differ significantly, the highest sustained action was observed for the F7 formulation.

Thus, a depot effect could be achieved using elastic liposomes, especially in the F7 elastic liposomal formulations. Since the F7 formulation is optimal in all aspects (size, shape, stability, EE, and drug release), results of this study recommend the F7 formulation for further release kinetic studies.

The release kinetics were further evaluated considering four different mathematical models including zero order, first order, Higuchi's equation, Hixson-Crowell, and Korsmeyer's equations and the selection was based on the comparisons of the relevant correlation coefficients and linearity tests as mentioned in Table 8.

Table 7 Ex vivo drug release profile of formulations

\begin{tabular}{|c|c|c|}
\hline \multirow{2}{*}{$\begin{array}{l}\text { Time } \\
\text { (min) }\end{array}$} & \multicolumn{2}{|c|}{ Percentage cumulative release $^{a}$} \\
\hline & Formulation F I & Formulation F7 \\
\hline 0 & 0 & 0 \\
\hline 5 & $9.405 \pm 1.34$ & $0.322 \pm 0.87$ \\
\hline 10 & $11.575 \pm 0.73$ & $7.758 \pm 2.52$ \\
\hline 15 & $12.697 \pm 0.58$ & $|3.092 \pm 1.9|$ \\
\hline 30 & $16.566 \pm 3.79$ & $16.307 \pm 1.56$ \\
\hline 45 & $20.147 \pm 0.57$ & $19.866 \pm 2.03$ \\
\hline 60 & $24.209 \pm 0.09$ & $26.254 \pm 0.97$ \\
\hline 120 & $34.436 \pm 0.64$ & $33.560 \pm 1.00$ \\
\hline 240 & $37.643 \pm 1.59$ & $39.561 \pm 1.33$ \\
\hline 480 & $46.601 \pm 1.84$ & $48.260 \pm 1.28$ \\
\hline 720 & $63.292 \pm 3.45$ & $52.255 \pm 1.65$ \\
\hline 1,440 & $71.088 \pm 1.62$ & $58.820 \pm 4.02$ \\
\hline
\end{tabular}




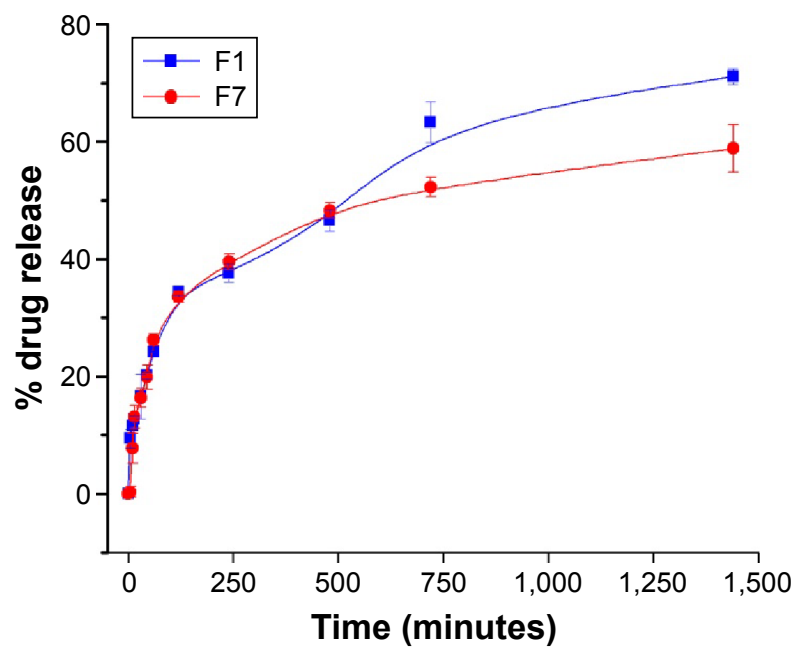

Figure 4 Comparison of release profile of both (FI and F7) formulations.

Release kinetics for the F7 formulation was studied using different kinetic equations, and the best fit equation was found to be the Higuchi matrix (with a high correlation, $\left.\left[r^{2}=0.891\right]\right)$ which means the drug release was by a diffusion controlled process based on Fick's law $(\mathrm{n}<0.5$ for Fickian diffusion).

\section{Conclusion}

Elastic liposomes are especially optimized particles or vesicles which can provide a novel solution for transport related problems. Elastic liposomes of Tramadol $\mathrm{HCl}$ were prepared and evaluated for different parameters like microscopy, particle size, shape, drug content, ex vivo release, zeta potential, etc. From the above observation, it can be concluded that sonication is an essential tool for preparation, and while comparing the EE, elastic liposomes containing PC:Span 80 (F7) at a ratio of 85:15 (100\%) showed the highest value with respect to all other formulations. The highest sustained action was observed for the F7 formulation. The optimized elastic liposomal formulation F7 followed the Higuchi equation and Fickian diffusion with release over 24 hours for tramadol $\mathrm{HCl}$.

Table 8 Kinetic analysis of F7 data of topical hydrogel formulations

\begin{tabular}{lll}
\hline Kinetic models & Slope & $\mathbf{r}^{2}$ \\
\hline Zero order & $0.005 x$ & 0.674 \\
First order & $0.000 x$ & 0.261 \\
Higuchi & $0.218 x$ & 0.891 \\
Korsmeyer-Peppas & $0.493 x$ & 0.562 \\
Hixson-Crowell & $0.000 x$ & 0.360 \\
\hline
\end{tabular}

Note: Results are in response to a linear regression analysis.

\section{Acknowledgments}

Lovely Professional University is acknowledged for the free access to facilities of the instruments and apparatus. The authors gratefully thank NIPER, Mohali for providing facilities for TEM, ultra centrifugation, particle size, and zeta potential analyses.

\section{Disclosure}

The authors report no conflicts of interest in this work.

\section{References}

1. Barry BW. Novel mechanisms and devices to enable successful transdermal drug delivery. Eur J Pharm Sci. 2001;14:101-114.

2. Cevc G, Vierl U, Mazgareanu S. Functional characterisation of novel analgesic product based on self-regulating drug carriers. Int J Pharm. 2008;360:18-28.

3. Cevc G, Mazgareanu S, Rother M, Vierl U. Occlusion effect on transcutaneous NSAID delivery from conventional and carrier-based formulations. Int J Pharm. 2008;359:190-197.

4. Cevc G. Material transport across permeability barriers by means of lipid vesicles. In: Hoff AV (series editor), Lipowsky R, Sackmann E (volume editors). Handbook of Biological Physics. Vol I. North-Holland, the Netherlands: Elsevier; 1995:465-490.

5. Jain S, Bhadra D, Jain NK. Transfersomes - a novel carrier for effective transdermal drug delivery. Adv Control N Drug Deliv. 2010;10: $427-451$.

6. Moore RA, McQuay HJ. Single-patient data meta-analysis of 3453 postoperative patients: oral tramadol versus placebo, codeine and combination analgesics. Pain. 1997;69:287-294.

7. Bachs L, England A, Morland J, Skurtveit S. The risk of motor vehicle accidents involving drivers with prescriptions for codeine or tramadol. Clin Pharmacol Ther. 2009;85(6):596-599.

8. Takeshita J, Litzinger MH. Serotonin syndrome associated with tramadol; prim care companion. J Clin Psychiatry. 2009;11:273.

9. El Maghraby GM, Williams AC, Barry BW. Oestradiol skin delivery from ultradeformable liposomes: refinement of surfactant concentration. Int J Pharm. 2000;196:63-74.

10. El Maghraby GM, Williams AC, Barry BW. Skin delivery of oestradiol from lipid vesicles: importance of liposome structure. Int J Pharm. 2000; 204:159-169.

11. El Maghraby GM, Williams AC, Barry BW. Interactions of surfactants (edge activators) and skin penetration enhancers with liposomes. Int J Pharm. 2004;276:143-161.

12. Elsayed MM, Abdallah OY, Naggar VF, Khalafallah NM. Deformable liposomes and ethosomes as carriers for skin delivery of ketotifen. Pharmazie. 2007;62:133-137.

13. Gupta PN, Mishra V, Rawat A, et al. Non-invasive vaccine delivery in transfersomes, niosomes and liposomes: a comparative study. Int J Pharm. 2005;293:73-82.

14. Song YK, Kim CK. Topical delivery of low-molecular-weight heparin with surface charged flexible liposomes. Biomaterials. 2006;27: 271-280.

15. Van den Bergh BAI, Wertz PW, Junginger HE, Bouwstra JA. Elasticity of vesicles assessed by electron spin resonance, electron microscopy and extrusion measurements. Int J Pharm. 2001;217:13-24.

16. Bergh BAI, Wertz PW, Junginger HE, Bouwstra JA. Elasticity of vesicle assessed by electron spin resonance, electron microscopy and extrusion measurements. Int J Pharm. 2001;217:13-24.

17. Dubey V, Mishra D, Asthana A, Jain NK. Transdermal delivery of a pineal hormone: melatonin via elastic liposomes. Biomaterials. 2006; 27:3491-3496.

18. Wang YY, Hong CT, Chiu WT, Fang JY. In vitro and in vivo evaluations of topically applied capsaicin and nonivamide from hydrogels. Int J Pharm. 2001;224:89-104. 
19. Pavelic Z. Liposomal gel with chloramphenicol characterization and in-vitro release. Acta Pharma. 2004;54:319-330.

20. Agarwal R, Katare OP, Vyas SP. Preparation and in vitro evaluation of liposomal/niosomal delivery systems for antipsoriatic drug dithranol. Int J Pharm. 2001;228:43-52.

21. Singh P, Roberts MS. Skin permeability and local tissue concentrations of nonsteroidal anti-inflammatory drugs after topical application. J Pharmacol Exp Ther. 1994;268:144-151.

22. Singh P, Roberts MS. Dermal and underlying tissue pharmacokinetics of lidocaine after topical application. J Pharm Sci. 1994;83:774-782.

23. Yu HY, Liao HM. Triamcinolone permeation from different liposome formulations through rat skin in vitro. Int J Pharm. 1996;127:1-7.

24. Honeywell-Nguyen PL, Frederik PM, Bomans PHH, Junginger HE, Bouwstra JA. The in vitro transport of pergolide from surfactant based elastic vesicles though human skin: a suggested mechanism of action. J Control Release. 2003;86:145-156.
25. Kim A, Lee EH, Choi SH, Kim CK. In vitro and in vivo transfection efficiency of a novel ultradeformable cationic liposome. Biomaterials. 2004;25:305-313.

26. Liu H, Pan WS, Tang R, Luo SD. Topical delivery of different acyclovir palmitate liposome formulations through rat skin in vitro. Pharmazie. 2004;59:203-206.

27. Gupta PN, Mishra V, Singh P, et al. Tetanus toxoid-loaded transfersomes for topical immunization. J Pharm Pharmacol. 2005;57:295-301.

28. Freitas C, Muller RH. Effect of light and temperature on zeta potential and physical stability in solid lipid nanoparticles dispersions. Int $J$ Pharm. 1998;168:221-229.
International Journal of Nanomedicine

\section{Publish your work in this journal}

The International Journal of Nanomedicine is an international, peerreviewed journal focusing on the application of nanotechnology in diagnostics, therapeutics, and drug delivery systems throughout the biomedical field. This journal is indexed on PubMed Central, MedLine, CAS, SciSearch ${ }^{\circledR}$, Current Contents ${ }^{\circledR} /$ Clinical Medicine,

\section{Dovepress}

Journal Citation Reports/Science Edition, EMBase, Scopus and the Elsevier Bibliographic databases. The manuscript management system is completely online and includes a very quick and fair peer-review system, which is all easy to use. Visit http://www.dovepress.com/ testimonials.php to read real quotes from published authors. 